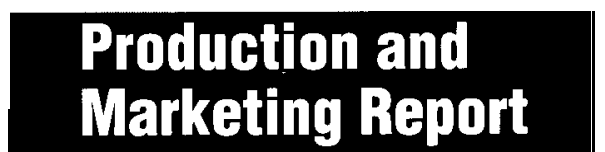

\section{Quality Indices and Sensory Scores Support Early Harvest of Pecans}

\author{
Juan L. Silva1, \\ Frank B. Matta ${ }^{2}$, and \\ Esteban A. Herrera ${ }^{3}$
}

Additional index winds. nut quality,

kernel quality, Caya illinoinensis

Summary. Pecans [ Carya illinoinensis (Wangenh. C.) Koch] were harvested weekly for 9 and 7 weeks until normal harvest time during 1986 and 1987, respectively. Kernels were tested for chemical, physical, and sensory properties. Moisture decreased from $13 \%$ at initial harvest time to $4 \%$ to $6 \%$ by normal harvest. Free fatty acids decreased from

'Food process engineer and associate professor, Department of Food Science and Technology, Mississippi State University, Mississippi State, MS 39762.

${ }^{2}$ Professor, Department of Horticulture, Mississippi State University, Mississippi State, MS 39762.

${ }^{3}$ Extension fruit specialist, Department of Agronomy and Horticulture, New Mexico State University, Las Cruces, NM 88003.

Research conducted at Mississippi State Univ. Use of trade names does not imply endorsement of the products named nor criticism of similar ones not named. Approved for publication as Journal article no. J-8650 of the Mississippi Agricultural and Forestry Experiment Station, Mississippi State Univ. Mississippi State, MS 39762. Research completed as part of the Mississippi Agricultural and Forestry Experiment Station project no. MIS-1029. We thank the Western Pecan Growers Association for their partial support Thanks also to Donna Bland for her typing and editing. The cost of publishing this paper was defrayed in part by the payment of page charges Under postal regulations, this paper therefore must be hereby marked advertisement solety to indicate this fact.
$0.5 \%$ to $0.2 \%$ by the third week before normal harvest. Tannins fluctuated, but averaged about $0.8 \%$. Hue angle remained constant from the fourth week to normal harvest. Shear force increased from 90 to $135 \mathrm{~N}$ by the second week before normal harvest. Pecans can be harvested about 2 weeks before normal harvest without significant quality deficiencies.

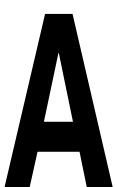

bout $80 \%$ of the world's pecan crop is from the United States, with New Mexico producing about $11 \%$. United States production in 1993 totaled 186 million $\mathrm{kg}$ compared to 127 million kg in 1983 (Peña, 1994). This increase in production along with imports has at times significantly decreased the price of nuts.

Mechanical harvesting and better handling equipment have enabled farmers to harvest nuts early. However, if pecans are harvested too early (before the shells turn brown) they have less meat, are light in weight, and difficult to shell (Woodroof and Heaton, 1961). Pecans harvested early provide better storage stability, improved color, and flavor stability (Heaton et al., 1975), Pecans harvested too early contain little oil, but, if harvest is delayed, nut quality decreases, as evidenced by mold growth and rancidity development (Love and Young, 1970). Unsaturated fatty acids comprise about $95 \%$ of the total fatty acids in mature pecan nuts (Herrera, 1983); thus, they are susceptible to oxidative rancidity. Lower kernel quality in lateharvested pecans may be caused by rewetting (uptake of moisture by the nuts after being dried).

Various studies on early harvesting of pecans on nut size, weight, moisture, fatty acid profile, sensory quality attributes, and nut and shell color have been published (Heaton and Beauchat, 1980; Heaton et al., 1975; Love and Young, 1971; Schaller, 1971; Smith and Loustalot, 1944).

The objective of this study was to determine the effect of early harvest on kernel quality of pecan cultivars as measured by chemical, physical, and sensory methods.

\section{Materials and methods}

'Ideal,' 'Wichita,' and 'Western Schley'('Western') pecans were harvested weekly during 1986 and 1987 from a Las Cruces, N.M., farm. Pecans were harvested at 1 -week intervals for 9 weeks starting on 30 Sept. and ending at normal harvest (25 Nov.), and for 7 weeks starting on $200 \mathrm{ct}$. and ending at normal harvest (1 Dec.) in 1986 and 1987 , respectively. Normal harvest was defined as the time when about $90 \%$ of nuts on a tree have split shucks and are shaken off the tree for immediate harvest. In-shell pecans were shipped to the Mississippi State Food Processing Laboratory 
Table 1. Cultivar and harvest time effects on moisture, appearance, and shear force of pecan kernels.

\begin{tabular}{|c|c|c|c|c|c|c|c|c|c|}
\hline \multirow{3}{*}{$\begin{array}{l}\text { Harvest } \\
\text { time }\end{array}$} & \multicolumn{3}{|c|}{ Moisture (\%) } & \multirow{2}{*}{\multicolumn{3}{|c|}{$\begin{array}{c}\text { Appearance }^{2} \\
\text { Cultivar } \\
\end{array}$}} & \multicolumn{3}{|c|}{ Shear force $\left(b_{b}\right)$} \\
\hline & \multirow[b]{2}{*}{ Wichita } & \multirow[b]{2}{*}{ Western Schley } & \multirow[b]{2}{*}{ Ideal } & & & & \multirow{3}{*}{ Wichita } & \multirow{3}{*}{ Western Schley } & \multirow{3}{*}{ Ideal } \\
\hline & & & & \multirow{2}{*}{$\begin{array}{r}\text { Wichita } \\
1986\end{array}$} & \multirow[t]{2}{*}{ Western Schley } & \multirow[t]{2}{*}{ Ideal } & & & \\
\hline & & & & & & & & & \\
\hline Sept. 30 & 13.0 & 12.2 & 13.3 & 2.3 & 4.0 & 3.7 & 30.1 & 26.2 & 25.9 \\
\hline Oct. 7 & 12.5 & 13.6 & 13.6 & 2.0 & 4.0 & 4.6 & 21.2 & 20.3 & 19.3 \\
\hline 14 & 11.7 & 122 & 9.5 & 2.7 & 4.0 & 4.2 & 21.6 & 23.2 & 256 \\
\hline 21 & 12.1 & 12.6 & 11.1 & 2.3 & 4.0 & 37 & 20.6 & 23.4 & 21.6 \\
\hline 28 & 10.2 & 12.0 & 12.5 & 2.2 & 3.6 & 3.8 & 23.6 & 22.6 & 24.4 \\
\hline Nov. 4 & 10.0 & 13.6 & 9.4 & 2.5 & 3.8 & 4.0 & 25.8 & 30.2 & 24.1 \\
\hline 11 & 7.7 & 10.2 & 6.9 & 2.7 & 4.3 & 4.0 & 28.5 & 30.2 & 32.8 \\
\hline 18 & 6.2 & 7.3 & 5.6 & 2.7 & 4.0 & 3.8 & 28.3 & 31.3 & 29.2 \\
\hline 25 & 5.0 & 7.1 & 4.7 & 2.8 & 3.8 & 2.8 & 28.7 & 31.9 & 30.3 \\
\hline $\operatorname{LSD}(0.05)$ & & 2.2 & & & 0.4 & & & 1.7 & \\
\hline & & & & 1987 & & & & & \\
\hline Oct. & 12.7 & 14.0 & 12.9 & --- & --- & -- & & & \\
\hline 27 & 12.5 & 13.7 & 12.6 & 3.0 & 3.8 & 3.4 & & & \\
\hline Nov. 3 & 12.2 & 13.9 & 12.5 & 2.8 & 4.3 & 3.4 & & & \\
\hline 10 & 8.9 & 13.0 & 9.9 & 2.4 & 39 & 3.4 & & & \\
\hline 17 & 6.3 & 7.2 & 6.4 & 2.5 & 4.0 & 3.3 & & & \\
\hline 24 & 5.5 & 6.4 & 5.9 & 2.6 & 3.9 & 4.1 & & & \\
\hline Dec. 1 & 37 & 34 & 3.5 & 3.1 & 3.1 & 3.8 & & & \\
\hline $\operatorname{LSD}(0.05)$ & & 2.2 & & & 0.6 & & & & \\
\hline
\end{tabular}

${ }^{2}$ Appearance 1 = small, shrivelled, 5 = large, full.

and stored at $2 \mathrm{C}$ for 3 days before shelling. Kernels were stored at $2 \mathrm{C}$ for sensory and physical analysis and $-18 \mathrm{C}$ for chemical analysis.

Average moisture content of the kernels was measured following Association for Official Analytical Chemists (AOAC) method 27.005 (AOAC, 1984). Free fatty acids (FFA), as percentage oleic acid (a measure of hydrolytic rancidity); peroxide (\%) (indicator of oxidative rancidity); and total tannins (\%)( bitter and astringent compound) were measured following AOAC methods 28.032, 28.025, and 30.018, respectively (AOAC, 1984).

Kernel color was determined using a color and color-difference meter (D-25; Hunterlab As- sociates, Reston, Va.) by measuring 'L' (brightness), 'a' (red-green), and 'b' (yellow-blue), Hue angle (color) was calculated as the $\tan ^{-1}(\mathrm{~b} / \mathrm{a})$ (Little, 1975). Shear force (firmness) was measured using a texture test system (FTC, Rockville, Md.) with a CS-1 shear cell, The ram stroke was 20 set and the load range $44 \mathrm{~N}\left(100 \mathrm{lb} \mathrm{b}_{\mathrm{t}}\right)$. Peak height

Table 2. Cultivar and harvest time effects on hue angle, Hunter 'L', and color of pecan kernels.

\begin{tabular}{|c|c|c|c|c|c|c|c|c|c|c|}
\hline \multirow{3}{*}{$\begin{array}{l}\text { Harvest } \\
\text { time }\end{array}$} & \multicolumn{3}{|c|}{ Hue angle } & \multicolumn{3}{|c|}{ Hunter 'L' value } & \multicolumn{4}{|c|}{ Color } \\
\hline & \multicolumn{10}{|c|}{ Cultivar } \\
\hline & Ideal & Wichita & Western Schley & Ideal & Wichita & Western Schley & Ideal & Wichita & Western & Schley \\
\hline \multicolumn{11}{|c|}{1986} \\
\hline Sept. 30 & 78.9 & 72.0 & 75.6 & 43.7 & 39.8 & 36.6 & 4.2 & 2.7 & & 3.2 \\
\hline \multirow[t]{4}{*}{ Oct. } & 74.2 & 72.2 & 73.6 & 36.5 & 36.4 & 36.2 & 32 & 1.5 & & 1.8 \\
\hline & 72.9 & 68.3 & 74.2 & 36.5 & 32.8 & 37.1 & 3.2 & 2.7 & & 3.5 \\
\hline & 74.1 & 69.4 & 72.4 & 34.9 & 36.6 & 35.9 & 2.3 & 2.7 & & 3.3 \\
\hline & 79.7 & 69.0 & 74.6 & 38.3 & 37.3 & 35.8 & 33 & 28 & & 1,8 \\
\hline \multirow[t]{4}{*}{ Nov. } & 72.5 & 69.1 & 71.2 & 37.8 & 39.7 & 38.5 & 3.2 & 22 & & 2.7 \\
\hline & 75.1 & 69.1 & 73.0 & 37.2 & 38.6 & 36.8 & 2.7 & 2.8 & & 3.2 \\
\hline & 75.3 & 70.5 & 72.0 & 40.3 & 38,2 & 35.6 & 3.2 & 4.0 & & 2.7 \\
\hline & 79.6 & 71.8 & 68.8 & 39.7 & 37.9 & 40.2 & 4.2 & 3.7 & & 4.2 \\
\hline \multirow[t]{2}{*}{ LSD (0.05) } & & 3.6 & & & 2.2 & & & 0.7 & & \\
\hline & \multicolumn{10}{|c|}{1987} \\
\hline \multirow[t]{2}{*}{ Oct. } & 57.9 & 59.0 & --- & 35.2 & 41.1 & --- & -- & $\cdots$ & & $\cdots$ \\
\hline & 57.3 & 61.3 & 52.1 & 30.1 & 42.9 & 31.6 & 3.4 & 3.6 & & 2.4 \\
\hline \multirow{4}{*}{ Nov. } & 59.6 & 60.7 & 62.5 & 40.2 & 39.4 & 39.9 & 3.0 & 34 & & 2.8 \\
\hline & 58.4 & 61.3 & 60.2 & 36.7 & 40.7 & 40.5 & 3.3 & 3.8 & & 2.8 \\
\hline & 59.0 & 61.9 & 59.6 & 38.9 & 44.4 & 37.2 & 3.3 & 40 & & 3.3 \\
\hline & 57.3 & 60.2 & 58.4 & 39.3 & 42.0 & 39.0 & 3.4 & 3.6 & & 3.9 \\
\hline Dec. 1 & 58.4 & 61.3 & 58.4 & 37.6 & 44.1 & 38.1 & 3.1 & 3.4 & & 3.3 \\
\hline LSD $(0.05)$ & & 2.1 & & & 4.1 & & & 0.5 & & \\
\hline
\end{tabular}


of the texturegram was used as the measure of shear force (Bourne, 1982).

Pecan nuts (two per replication) were rated on appearance (size, shape, wholeness) and color (browning) by an experienced six-member panel. A five-point rating scale was used in each category, with $5=$ excellent and $1=$ poor (Larmond, 1977).

Data for both years were arranged in a $3 \times 9$ (or $3 \times 7$ in 1987) split-plot arrangement in a randomized complete block, with 'Ideal', 'Wichita', and 'Western' as whole plots and harvest times as subplots each week for 9 or 7 weeks until normal harvest. Both years included three replications per treatment. Data were analyzed following general linear model procedures for analysis of variance.

\section{Results and discussion}

Kernel moisture was greatest in September and October and decreased in November in both years, In 1986, kernel moisture between harvest and 1 week before normal harvest did not differ. In 1987, kernel moisture was greater at all harvests before normal harvest (Table 1) Consistent with this study, kernel moisture has been reported to be greater in early harvested pecans and has been shown to decrease with harvest time (Love and Young, 1970). Pecan kernels are normally artificially dried to $4 \%$ moisture if moisture is higher. Pecans at normal harvest would have needed drying in 1986 but not in 1987. All pecans harvested before normal harvest would need a certain amount of drying depending on harvest time.
There were no cultivar differences in kernel moisture.

Sensory scores for kernel appearance of 'Ideal' in 1986 and 1987 indicate that no differences occurred among the November harvests, which included normal harvest (Table 1). In 1987, sensory scores for appearance of 'Wichita' at normal harvest did not differ from kernel appearance 2 weeks before normal harvest. In 1986, 'Western' kernel appearance was rated lower in November compared to earlier harvests in 1986, indicating better appearance at earlier harvests. In 1987, kernel appearance of 'Western' was not influenced by harvest date except on 24 Nov., when kernels were rated higher but not different from normally harvested (1 Dec.) pecans, In 1986, kernel appearance of 'Wichita' was not influenced by harvest date. In 1987, normally harvested kernels did not differ in appearance compared to early harvested kernels, except kernels harvested 28 Oct., which were rated better.

Kernel shear force was measured in 1986 only. Except for the 30 Sept. harvest, shear force for all cultivars was less in October and increased during November (Table 1). No differences in shear force were recorded among the November harvests, which included normal harvest. Therefore, kernel firmness would not be influenced by early harvest.

Hue angle values are indicators of color based on a scale of yellow to red. The larger the value the less red color. In 1986, kernel hue angle values for 'Ideal' were greater at normal harvest compared to earlier harvests in November, indi- cating redder (browner) kernels. However, no differences were detected in 1987 (Table 2). Kernel hue angle values for 'Wichita' were not influenced by harvest time in 1986. Except for lighter (less red) kernels on 20 Oct. 1987, 'Wichita' had lighter color kernels at normal harvest ( $25 \mathrm{Nov}$.) compared to the remaining harvests. In 1987, 'Western' exhibited higher kernel hue angle values on 27 Oct. compared to the remaining harvests. Kernel hue angle values among the November harvests and normal harvest (1 Dec.) did not differ.

There was a cultivar response with respect to kernel hue angle values (Table 2). In 1986, 'Ideal' had redder kernels and 'Western' had lighter kernels at normal harvest, and harvest date did not influence hue angle values of 'Wichita' The response also varied by year; in 1987, hue angle values of 'Ideal' were not influenced by harvest date. 'Wichita' had lighter colored kernels only on 20 Oct., and 'Western' had redder kernels only on 27 Oct. Since hue angle values among the November harvests did not differ for 'Wichita' in either year, kernel color should not have affected quality. However, color quality of 'Ideal' and 'Western' was affected by harvest date and the response was cultivar-dependent. Variations in nut color can result from seasonal variation (Woodroof, 1967), cultivar differences (Kays and Wilson, 1978), and storage conditions (Forbus et al., 1983).

High Hunter CL' values indicate color brightness. In 1986, 'Western' had brighter kernels at normal harvest (25 Nov.) compared to kernels from previous harvests, and no differences existed among the previous harvests (Table 2). In 1987,

Table 3. Cultivar and harvest time affects on free fatty acids (FFA), peroxide value, and tannins of pecan kernels.

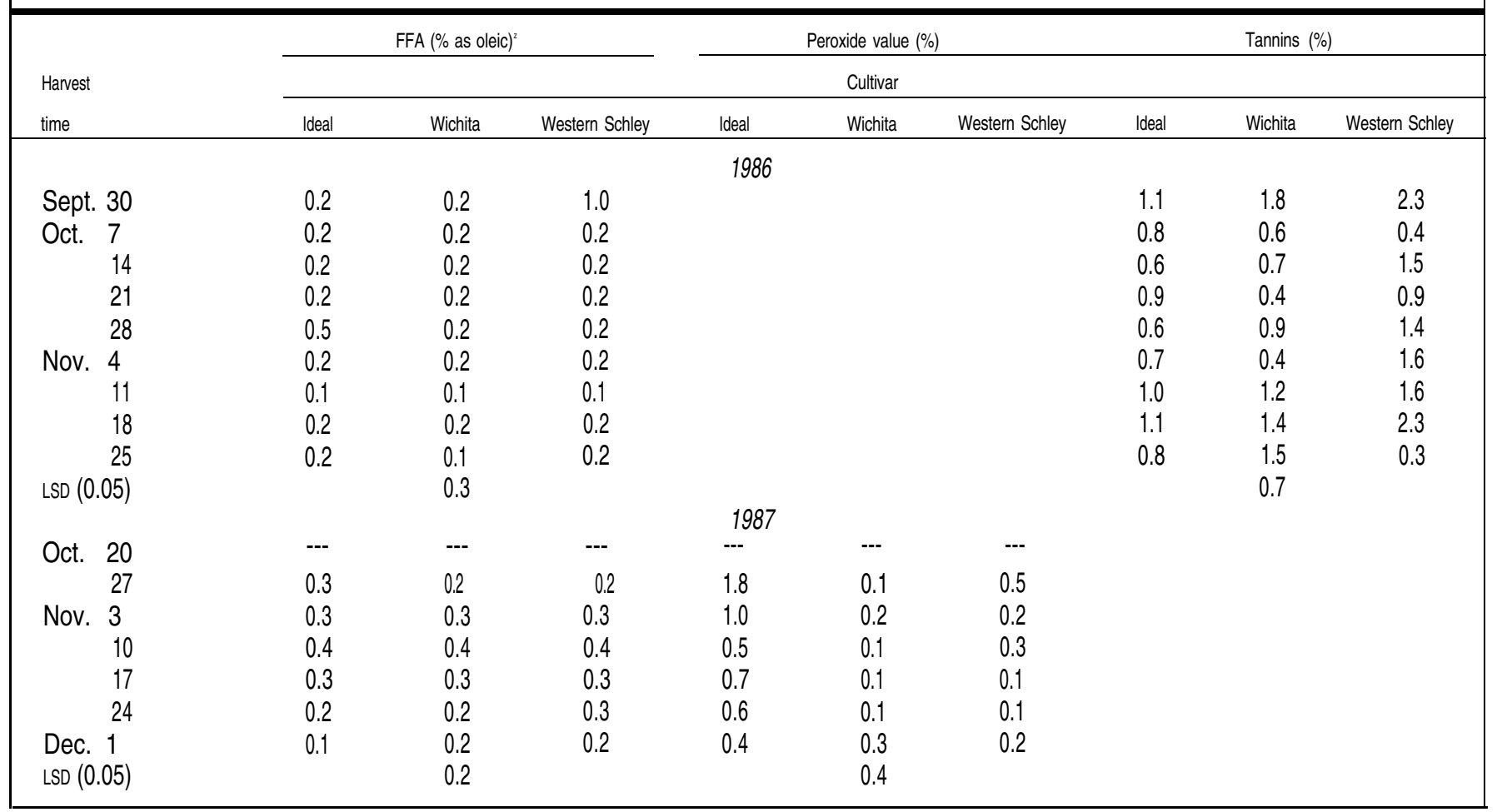


however, 'Western' Hunter 'L' values did not differ in November or December (normal harvest). Hunter 'L' values for 'Ideal' and 'Wichita' in 1986 were initially high, decreased in October, and increased again in November. In 1987, no differences in 'Ideal' Hunter 'L' values were found in November or December (normal harvest). 'Wichita' Hunter 'L' values were not influenced by harvest date in 1987.

Sensory scores for color in 1986 showed that 'Ideal' had brown, more brightly colored kernels at normal harvest (25 Nov.) and 30 Sept. compared to kernels harvested during the season (Table 2). Color for 'Ideal' in 1987 was not influenced by harvest date. In 1986, color of 'Western' was rated low (dark, dull) on 7 and 28 Oct., and no differences were detected at the remaining harvest times except at normal harvest, when the kernels were rated higher (browner and brighter). In 1987, kernel color of 'Western' was rated low on 27 Oct. and 3 and 10 Nov., but received higher color rating at normal harvest and 2 weeks before normal harvest. In 1986, color rating of 'Wichita kernels did not differ, except on 7 Oct. and 4 Nov., when they were rated lower than the remaining harvests including normal harvest (25 Nov.). In 1987, color ratings of 'Wichita' as influenced by harvest date did not differ, except on 17 Nov., when color ratings were higher compared to normally harvested pecans. There was a cultivar and a year response with respect to sensory scores for color; 'Ideal' had brighter kernel color at normal harvest in 1986 but color was not affected in 1987. 'Western' had brighter color at normal harvest in 1986 and brighter color 2 weeks before normal harvest and at normal harvest in 1987. 'Wichita' had brighter kernels at normal harvest and 1 week before normal harvest in 1986 and brighter kernels 2 weeks before normal harvest. In general, sensory scores for color indicate that kernels would have better color at earlier harvests and that early harvest would not be detrimental to color.

Free fatty acids (as percentage oleic) did not differ with harvest time (Table 3). Woodroof and Heaton (1961) stated that free fatty acid levels above $0.4 \%$ may be associated with low-quality pecan nuts. In this study, free fatty acid levels were $0.11 \%$ to $0.35 \%$. Therefore, free fatty acids should not have affected pecan quality in this study.

Tannin content was measured only in 1986 and, for 'Ideal', was not influenced by harvest time. In 'Wichita', tannin content was higher in September compared to October and increased again the last three harvests in November (Table 3). Tannin content among the November harvests did not differ, For 'Ideal' and 'Wichita', when harvesting early in November ( 2 or 3 weeks before normal harvest), tannins should not affect kernel quality.
In 'Western', however, the increase in tannins before harvest may contribute to kernel browning and bitterness (Bate-Smith, 1972). For 'Western', tannin content was higher in September compared to October, increased in November, and was lowest at normal harvest. Tannins are partly responsible for kernel coloration and flavor stability (Heaton et al., 1975). Polles etal. (1981)found that tannins in 31 pecan cultivars peaked at optimum harvest and were $0.70 \%$ to $1.71 \%$, They also reported that 'Wichita' contained $1.4 \%$ tannins, which was higher than most other cultivars. In this study, tannins were $0.30 \%$ to $2.30 \%$

Peroxide values, which measure oxidative rancidity and off-flavor, were taken in 1987. 'Ideal' had greater peroxide levels in October, indicating potential off-flavor due to oxidation compared to November and December harvests (Table 3). Peroxide values in November and at normal harvest (1 Dec.) did not differ. Peroxide values of 'Wichita' and 'Western' were not influenced by harvest time. Williams et al. (1977) reported peroxide values of $0.97 \%$ to $2.8 \%$ in various pecan Cultivars during storage. Peroxide values in this study were $0.07 \%$ to $1.82 \%$. Low peroxide values in this study, plus the fact that no differences existed at least 3 weeks before normal harvest, suggest that peroxide values should not have affected kernel quality.

Results of this study indicate that free fatty acids, tannin content, peroxide values, hue angle values, Hunter 'L' values, and shear force did not show that kernel quality of pecans was reduced by harvesting early in November. In addition, sensory scores for appearance and color indicated that pecans harvested early would have better kernel appearance and color than pecans harvested at normal harvest. Therefore, the quality indices and sensory scores in this study support early harvest of pecans.

\section{Literature Cited}

Association of Official Analytical Chemists 1984. Official methods of analysis. 14th ed. Assn of Offic. Anal. Chemists, Washington, D.C.

Bate-Smith, E.C. 1972. Phytochemical ecology. Academic, New York. p. 55

Bourne, M.C. 1982. Food texture and viscosity, Academic, New York,

Forbus, Jr., W.R., S.D. Senter, and R.L. Wilson. 1983, Cultivars, processing, and storage effects on kernel color. J. Food Sci. 48:1646.
Heaton, E.K. and L.R. Beauchat 1980. Quality characteristics of high-moisture pecans stored at refrigeration temperatures. J. Food Sci. 45:255.

Heaton, E.K., R.E. Worthington, and A.L. Shewfelt. 1975. Pecan nut quality. Effect of time of harvest on composition, sensory and quality characteristics. J. Food Sci. 40:1260.

Herrera, E. 1983. Storing pecans, New Mexico State Univ. Coop. Ext. Serv., Las Cruces, Ph 4701, Guide H-620.

Kays, S.J. and D.M. Wilson. 1978. Genotype variation in pecan kernel color and color stability during storage. J. Amer. Soc. Hort. Sci. 103:137.

Larmond, E. 1977. Laboratory methods for sensory evaluation of food, Pub. 1637 Canada Dept. Agr., Ottawa, Canada,

Little, A.C. 1975. Off on a tangent. J. Food Sci. 40:410.

Love, J.E. and W.A. Young. 1970. Harvest dates and pecan quality studied. Pecan Quarterly (Nov.):7.

Peña, J.G. 1994. The 1993 pecan tree nut marketing season - an overview of production, prices and the pecan market collapse. Proc. 28th Western Pecan Conf., New Mexico State Univ., Las Cruces.

Polles, S.G., B.W.(Hanny, and A.J. Harvey, 1981, Condensed tannins in kernels of thirty-one pecan [Carya illinoensis (Wangenh) K. Koch.] cultivars. J. Agr. Food Chem. 29:196.

Schaller, C.C. 1971. Effect of shuck disease on ripening and filling of nuts of Carya illinoensis (Wang,) Koch cv. Success, HortScience 6:406.

Smith, C.L. and A. Loustalot. 1944. Effects of harvest date and curing on the composition and palatability of pecan nuts. J. Agr. Res. 68:395.

Williams, P.F., R.J. Curtis, L.S. Burgess, and N.J. Bunker. 1977. Pecans, handling storage, processing and utilization. Georgia Agr. Expt. Sta., Athens.

Woodroof, J.G. 1967. Tree nuts: Production, processing, products. vol. 2. AVI Publ. Co., Westport, Corm.

Woodroof, J.G, and E.K. Heaton. 1961. Pecans for processing. Georgia Agr. Expt. Sta., Univ. of Georgia College of Agr., Bul. N.S. 80. 